\title{
Retrieved wind speed from the Orbiting Carbon Observatory-2
}

\author{
Robert R. Nelson ${ }^{1}$, Annmarie Eldering ${ }^{1}$, David Crisp ${ }^{1}$, Aronne J. Merrelli ${ }^{2}$, and Christopher W. O'Dell ${ }^{3}$ \\ ${ }^{1}$ Jet Propulsion Laboratory, California Institute of Technology, Pasadena, CA, USA \\ ${ }^{2}$ Space Science and Engineering Center, University of Wisconsin-Madison, Madison, WI, USA \\ ${ }^{3}$ Cooperative Institute for Research in the Atmosphere, Fort Collins, CO, USA
}

Correspondence: Robert R. Nelson (robert.r.nelson@jpl.nasa.gov)

Received: 8 May 2020 - Discussion started: 11 June 2020

Revised: 31 August 2020 - Accepted: 4 November 2020 - Published: 18 December 2020

\begin{abstract}
Satellite measurements of surface wind speed over the ocean inform a wide variety of scientific pursuits. While both active and passive microwave sensors are traditionally used to detect surface wind speed over water surfaces, measurements of reflected sunlight in the near-infrared made by the Orbiting Carbon Observatory-2 (OCO-2) are also sensitive to the wind speed. In this work, retrieved wind speeds from OCO-2 glint measurements are validated against the Advanced Microwave Scanning Radiometer-2 (AMSR2). Both sensors are in the international Afternoon Constellation (A-Train), allowing for a large number of co-located observations. Several different OCO-2 retrieval algorithm modifications are tested, with the most successful being a single-band Cox-Munk-only model. Using this, we find excellent agreement between the two sensors, with OCO-2 having a small mean bias against AMSR2 of $-0.22 \mathrm{~m} \mathrm{~s}^{-1}$, an RMSD of $0.75 \mathrm{~m} \mathrm{~s}^{-1}$, and a correlation coefficient of 0.94 . Although OCO-2 is restricted to clear-sky measurements, potential benefits of its higher spatial resolution relative to microwave instruments include the study of coastal wind processes, which may be able to inform certain economic sectors.
\end{abstract}

Copyright statement. (C) 2020 California Institute of Technology. Government sponsorship acknowledged.

\section{Introduction}

Surface wind speed has been measured by satellites going back nearly half a century. These measurements have proven extremely valuable in improving weather and climate mod- els while advancing our understanding of oceanic and atmospheric physics. Both active and passive sensors are used to estimate wind speeds, and these measurements are typically made in the microwave frequency range in order to penetrate through clouds and most precipitation. Technically, these satellites are sensitive to the surface roughness. Ocean surfaces respond quickly to the movement of the air above them, and thus the surface roughness pattern is a function of both wind speed and wind direction. This wind speed measurement technique is limited in that it does not work over land or ice surfaces.

Active instruments, including scatterometers (e.g., SeaWinds - Spencer et al., 2000; ASCAT - Figa-Saldaña et al., 2002; RapidScat - Durden and Perkovic-Martin, 2017), altimeters (e.g., SEASAT - Born et al., 1979; SARAL-AltiKa - Lillibridge et al., 2014), and synthetic aperture radars (e.g., RADARSAT-1 - Parashar et al., 1993; ALOS PALSAR Rosenqvist et al., 2007) estimate wind speed and sometimes direction by sending electromagnetic pulses to the surface and then detecting and characterizing the backscattered radiation. Wind speed (but not direction) can also be estimated from measurements of radiation obtained by passive microwave instruments that operate at a variety of frequencies. The characteristics of this radiation depend on windinduced effects on surface roughness and the production of white caps (Bourassa et al., 2010), so typically a radiative transfer model is used to estimate wind speed from these emission characteristics (e.g., Wentz, 1997; Meissner and Wentz, 2012). Examples of passive sensors include the Special Sensor Microwave Imager (SSM/I; Hollinger et al., 1990; Wentz, 1997), the Special Sensor Microwave Imager Sounder (SSMIS), the Tropical Rainfall Mission Microwave Imager (TMI; Wentz, 2015), the Global Precipitation Mis- 
sion (GMI; Draper et al., 2015; Wentz and Draper, 2016), and the Advanced Microwave Scanning Radiometers (AMSR-E and AMSR2; Imaoka et al., 2010). They all measure at microwave frequencies from 6 to $37 \mathrm{GHz}$ at both vertical and horizontal polarizations, allowing for the removal of atmospheric attenuation effects. The spatial resolution of these passive sensors typically ranges from $20-35 \mathrm{~km}$.

In addition to missions specifically designed to measure wind speed, many spaceborne sensors that measure reflected sunlight in the visible or near-infrared must have some way of accounting for reflection off of specular surfaces such as the ocean. The Orbiting Carbon Observatory-2 (OCO2; Crisp et al., 2008) is one such instrument. It measures reflected sunlight in three near-infrared bands and uses a Cox-Munk (Cox and Munk, 1954) sea surface slope model to estimate reflectance when over water surfaces. These reflectances are primarily a function of illumination, viewing geometry, and wind speed. However, no effort has been made to validate the wind speed estimates from OCO-2 until now.

Section 2 discusses the two primary datasets used in this validation study: OCO-2 and AMSR2. Section 3 describes the OCO-2 retrieval and, specifically, the wind speed derivation. Section 4 presents results from four different OCO-2 retrieval variants and show how they compare to AMSR2 wind speeds. Finally, Sect. 5 summarizes the results and discusses the potential scientific utility of OCO-2 wind speed measurements.

\section{Data}

In this work we compare wind speed estimates from spectroscopic observations from OCO-2 to passive microwave observations from the Advanced Microwave Scanning Radiometer 2 (AMSR2) on the Japanese Global Change Observation Mission for Water-1 (GCOM-W1) satellite. Both satellites are in a unique sun-synchronous polar orbit known as the Afternoon Constellation (A-Train) (L'Ecuyer and Jiang, 2010), which enables excellent co-location in both time and space. AMSR2 is approximately $5 \mathrm{~min}$ behind OCO-2 and has a swath width of $1450 \mathrm{~km}$, resulting in near global coverage every day. OCO-2 measures eight adjacent footprints, each with a resolution of approximately $1.25 \mathrm{~km}$ by $2 \mathrm{~km}$ at nadir, resulting in a swath width of about $10 \mathrm{~km}$. It has a repeat cycle of $16 \mathrm{~d}$ and makes about 1 million observations a day. Over water surfaces, which are relatively dark in the near-infrared, OCO-2 changes its viewing geometry in order to view a surface track near the much brighter sun glint spot (rather than nadir) in order to significantly increase the measured signal.

The AMSR2 wind speed product used for validation in this work is from Remote Sensing Systems (RSS; Meissner and Wentz, 2012). RSS provides two standard rainfree radiometer wind speed products: low-frequency and medium-frequency products. Both are available on a $0.25^{\circ}$ latitude-longitude grid. The low-frequency product uses microwave channels at $10.7,18.7,23.8$, and $36.5 \mathrm{GHz}$, while the medium-frequency product uses only 18.7, 23.8, and $36.5 \mathrm{GHz}$. Each product has its own benefits and drawbacks. For example, the low-frequency product is less impacted by the atmosphere and rain but is affected by radio frequency interference in the $10.7 \mathrm{GHz}$ channel as well as sun glint effects. The medium-frequency product has a higher effective spatial resolution and is less affected by ice and land contamination, but it is slightly noisier than the low-frequency product. Because of this, the comparisons presented here use the medium-frequency AMSR2 wind speed as the primary reference product. However, we briefly discuss results from the low-frequency product in Sect. 4.4.

No temporal threshold was needed for co-locating OCO-2 and AMSR2, as the nature of both satellite's scanning patterns results in the difference in time between a given OCO2 footprint and an AMSR2 grid cell ranging from 6 min behind to 4 min ahead. While each OCO-2 footprint typically falls within a $0.25^{\circ}$ by $0.25^{\circ}$ AMSR2 grid cell, a distance threshold of $<0.1^{\circ}$ was implemented to ensure that both instruments were observing approximately the same location. As GCOM-W1 was launched in 2012 and OCO-2 in 2014, the co-located data used in this study ranged from September 2014 to January 2019.

The accuracy of the AMSR2 wind speed product is fairly well characterized and is on the order of $1-1.5 \mathrm{~m} \mathrm{~s}^{-1}$ for wind speeds of 0-15 m s ${ }^{-1}$ (Wentz, 1997; Mears et al., 2001; Kachi et al., 2013; Ebuchi, 2014; Ricciardulli and Wentz, 2015; Wentz et al., 2017). RSS inter-calibrates several microwave radiometers; thus, conclusions about errors for one satellite are typically true for the entire suite of radiometers in a given study. Other validation work includes Kachi et al. (2013), who compared them to buoy wind speeds and found a root mean square deviation (RMSD) of $1.12 \mathrm{~m} \mathrm{~s}^{-1}$. Additionally, Ebuchi (2014) estimated the RMSD against buoy data to be $0.99 \mathrm{~m} \mathrm{~s}^{-1}$ for the RSS low-frequency product and $1.06 \mathrm{~m} \mathrm{~s}^{-1}$ for the medium-frequency product. In general, the accuracy of microwave radiometers tends to degrade when viewing rainy scenes. However, OCO-2 only returns useful data in cloud-free conditions; this should not be an issue for this comparison, because the co-location in space should be close enough such that both instruments are viewing cloudand rain-free scenes. Finally, while we recognize that buoys are generally considered the best validation metric, we forego them here in favor of AMSR2 because of its excellent colocation with OCO-2 in both time and space.

\section{OCO-2 retrieval algorithm}

OCO-2 measures reflected sunlight in three near-infrared bands: the molecular oxygen $\left(\mathrm{O}_{2}\right)$ A-band at $0.765 \mu \mathrm{m}$, a weakly absorbing carbon dioxide $\left(\mathrm{CO}_{2}\right)$ band at $1.61 \mu \mathrm{m}$, and a strongly absorbing $\mathrm{CO}_{2}$ band at approximately $2.06 \mu \mathrm{m}$. 
Coincident high-resolution $(\lambda / \Delta \lambda \sim 17000-19000)$ spectra collected in these three channels are combined to form soundings that are analyzed with a remote sensing retrieval algorithm to estimate the column-averaged dry-air mole fraction of $\mathrm{CO}_{2}\left(X_{\mathrm{CO}_{2}}\right)$ along with several other atmosphere and surface state properties that affect the measured radiances. In short, the retrieval algorithm starts with an assumed state vector containing a priori values and corresponding uncertainties and uses a full-physics surface-atmosphere radiative transfer model and an instrument model to simulate the observed spectra. It then uses optimal estimation (Rodgers, 2000) to iteratively update the state vector properties to minimize a cost function that reduces differences between measured and modeled radiance spectra within the constraints of the specified uncertainties. The final result is an optimized state vector, which is a weighted combination of information from the measurements themselves and the a priori values, and a posteriori uncertainty for each state vector element. Full details of the process and the state vector elements can be found in O'Dell et al. (2018). The current OCO-2 algorithm, version 9 (B9) of the Atmospheric Carbon Observations from Space (ACOS; O'Dell et al., 2012; Crisp et al., 2012), contains a state vector with approximately 55 elements including a 20-level $\mathrm{CO}_{2}$ profile, band-dependent albedos and albedo slopes, surface pressure, five cloud and aerosol types, etc. Over ocean, a wind speed scalar is also retrieved.

\subsection{Wind speed retrievals}

Over liquid water surfaces, the OCO-2 retrieval algorithm assumes that the surface reflectance could be simulated by a combination of two surface types: a Cox-Munk distribution of planar facets and a Lambertian surface. The Cox-Munk parameterization (Cox and Munk, 1954) was developed from the brightness distribution in 29 aerial photographs of sunlight reflected off of the ocean near Hawaii over a $20 \mathrm{~d}$ period. Their observations gave a distribution of wind-generated sea surface slopes that could be approximated by a Gaussian and expressed by a Gram-Charlier expansion. They also found that the mean square slope parameter, which describes the surface roughness in their photographs, could be related to wind speed to a first-order approximation using a simplified isotropic (independent of wind direction) function of the following form:

$\sigma_{\mathrm{cm}}^{2}=0.003+5.12 \times 10^{-3} U$,

where $U$ is wind speed (in m s${ }^{-1}$ ) and $\sigma_{\mathrm{cm}}^{2}$ is the mean square slope. This empirical model describes the probability that the sea surface will be oriented to cause sun glint, depending on the wind speed. Further details can be found in Cox and Munk (1954), Su et al. (2002), Kay et al. (2009), Monzon et al. (2006), and others. The Cox-Munk parameterization requires a refractive index in each band in order to produce an appropriate reflectance. Values for water are used: 1.331, 1.318, and 1.303 in the $\mathrm{O}_{2} \mathrm{~A}$-band, weak $\mathrm{CO}_{2}$ band, and strong $\mathrm{CO}_{2}$ band, respectively (Hale and Querry, 1973), with an adjustment made for sea water (Friedman, 1969; McLellan, 1965; Sverdrup et al., 1942). The Cox-Munk model was developed from measurements made at $12.5 \mathrm{~m}(41 \mathrm{ft})$, while surface wind speed products, including those provided by RSS, are typically reported at $10.0 \mathrm{~m}$. Thus, we use a $\log$ wind profile assumption to convert the $12.5 \mathrm{~m}$ wind speed values to $10.0 \mathrm{~m}$ above the surface:

$U=\frac{u_{*}}{k} \ln \left(\frac{z}{z_{0}}\right)$,

where $u_{*}$ is the friction velocity, $z_{0}$ is the aerodynamic roughness length, and $k$ is the von Kármán constant. Rearranging and solving for the wind speed at $10.0 \mathrm{~m}$ with a $z_{0}$ of 0.009 (Stull, 1988) gives a scaling factor of 0.9766 to convert winds at 12.5 to $10.0 \mathrm{~m}$.

While the Cox-Munk surface parameterization should be sufficient to describe reflection off of a water surface, a Lambertian component was added, because the ACOS retrieval is unable to perfectly fit the continua in all three bands with one free parameter (wind speed) (Crisp et al., 2017). Thus, a Lambertian albedo and albedo slope (a linear slope across the band added to the albedo magnitude) are solved for in all three bands. This results in seven variables being used over water to describe the surface. Because the Lambertian component is only being included to make a small difference in the fit (the Cox-Munk wind speed should do most of the work), the a priori albedo values are set to 0.02 . Additionally, the strong $\mathrm{CO}_{2}$ band albedo is fixed because various tests revealed that the retrieval often wanted to solve for negative albedos in that band. The likely reason for this is a $6 \%-8 \%$ overestimate in the solar flux, which will be fixed in the upcoming version of ACOS. The current solution to the issue is to simply not let it retrieve that value. The $1 \sigma$ a priori uncertainty on the albedos in the $\mathrm{O}_{2}$ A-band and weak $\mathrm{CO}_{2}$ band is 0.2 . The albedo slopes in all three bands have a prior value of 0.0 and a prior uncertainty of 1.0. The a priori wind speed is taken from the Goddard Earth Observing System Model, Version 5 with Forward Processing for Instrument Teams (GEOS-5 FP-IT; Rienecker et al., 2008) with a $1 \sigma$ a priori uncertainty of $6.325 \mathrm{~m} \mathrm{~s}^{-1}$.

\section{Results}

We evaluated the wind speed performance of the production OCO-2 ACOS B9 retrieval algorithm along with three modifications to this algorithm. All of the OCO-2 wind speed measurements were derived from sun glint measurements over water and have been scaled from 12.5 to $10.0 \mathrm{~m}$, as discussed in Sect. 3.1. Additionally, the B9 lite file $X_{\mathrm{CO}_{2}}$ quality flag was applied in order to remove poor-quality soundings. Details can be found in O'Dell et al. (2018) and Taylor et al. (2016), but in general the filtering process is designed to remove cloudy and aerosol-laden scenes and scenes with 


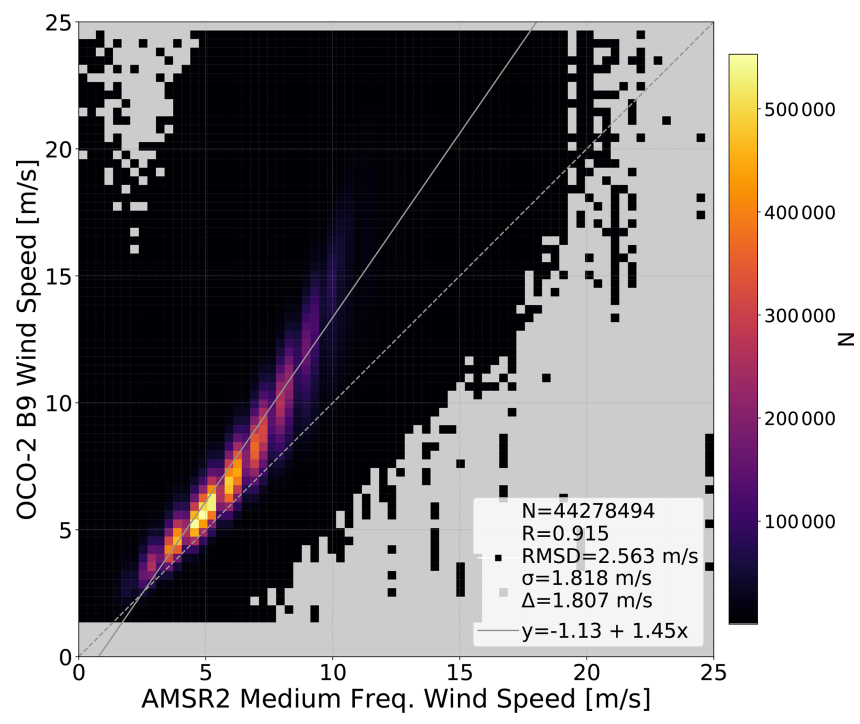

Figure 1. Heatmap of OCO-2 B9 wind speed compared to AMSR2 medium-frequency wind speed. The B9 lite file quality flag has been applied, along with a height scaling. $N$ is the number of retrievals, $R$ is the correlation coefficient, RMSD is the root mean square deviation of the two datasets, $\sigma$ is the standard deviation between the two datasets, $\Delta$ is the mean difference, the dashed line is a one-to-one line, and $y$ is a linear fit plotted as a solid line.

low signal levels. The three additional tests were an update of the solar continuum (Sect. 4.2), a three-band Cox-Munkonly retrieval (Sect. 4.3), and a single-band Cox-Munk-only retrieval (Sect. 4.4).

\subsection{B9 wind speed}

The OCO-2 B9 wind speed comparison to the AMSR2 wind speed is shown in Fig. 1. The benefit of the two instruments being adjacent in time and space can be seen, as over 44 million co-located measurements are plotted. There is generally low scatter and good agreement, but the OCO-2 estimates have a high bias that increases at higher wind speeds. The RMSD is $2.56 \mathrm{~m} \mathrm{~s}^{-1}$ with a mean positive bias of $1.8 \mathrm{~m} \mathrm{~s}^{-1}$. Measurements below $1.5 \mathrm{~m} \mathrm{~s}^{-1}$ for OCO-2 were filtered out in this B9 dataset, because they were correlated with poorquality $X_{\mathrm{CO}_{2}}$ retrievals. However, the difference between retrieved OCO-2 and AMSR2 wind speeds is not correlated with $X_{\mathrm{CO}_{2}}$ errors (not shown). This was also checked for the upcoming ACOS B10 retrieval, with no correlation being found.

\subsection{TSIS-SIM solar fluxes}

For all OCO-2 ACOS product versions before B10, the topof-atmosphere solar flux spectrum was derived by convolving a high-resolution empirical solar line transmission spectrum (Geoffrey Toon, personal communication, 2016) with a radiometrically calibrated solar continuum fit to the ATmo-

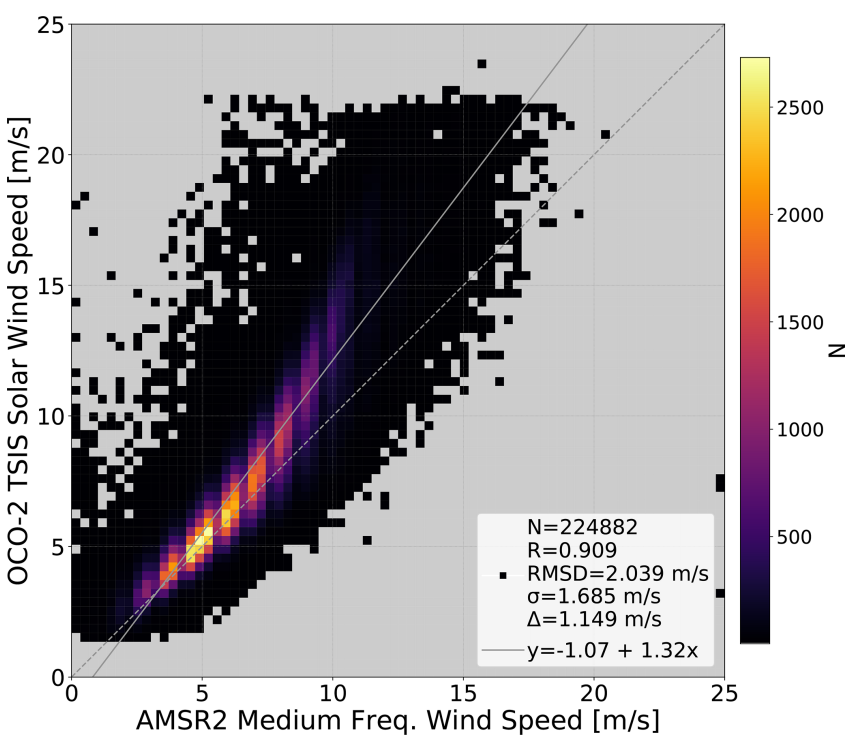

Figure 2. Heatmap of OCO-2 TSIS solar wind speed compared to AMSR 2 medium-frequency wind speed. The B9 lite file quality flag and preliminary B10 quality flag have been applied, along with a height scaling. $N$ is the number of retrievals, $R$ is the correlation coefficient, RMSD is the root mean square deviation of the two datasets, $\sigma$ is the standard deviation between the two datasets, $\Delta$ is the mean difference, the dashed line is a one-to-one line, and $y$ is a linear fit plotted as a solid line.

spheric Laboratory for Applications and Science-3 (ATLAS3) SOLar SPECtrum (SOLSPEC), which flew on the Space Shuttle (Thuillier et al., 2003). More recent measurements of the solar spectra from instruments deployed on the International Space Station (ISS) (Meftah et al., 2017) show that the ATLAS-3 SOLSPEC results overestimate the fluxes by $4 \%-8 \%$ in the $\mathrm{OCO}-2 \mathrm{CO}_{2}$ bands.

As a part of the ACOS B10 development, new solar flux spectra were generated to better estimate of the top-ofatmosphere solar flux. This update replaces the ATLAS-3 SOLSPEC continuum with a fit to the new reference solar spectrum based on data from the Total and Spectral Solar Irradiance Sensor (TSIS) Spectral Irradiance Monitor (SIM) onboard the ISS. The OCO- 2 continuum values were then scaled to match the new TSIS data, with the hope that a better band-to-band solar calibration would lead to a reduction in the Lambertian component over water surfaces and general improvements to the retrieval otherwise. Figure 2 demonstrates how the TSIS solar continuum affects the retrieved wind speed over water surfaces. Compared to Fig. 1, we see a reduction in the overall wind speed bias from +1.81 to $+1.15 \mathrm{~m} \mathrm{~s}^{-1}$ and a small improvement in the RMSD and scatter. The TSIS solar continuum test and the following retrieval modification tests were run on a relatively small dataset, but the statistics are similar when comparing the difference between OCO-2 B9 and AMSR2 on a comparably sampled dataset. This smaller dataset was specifically de- 


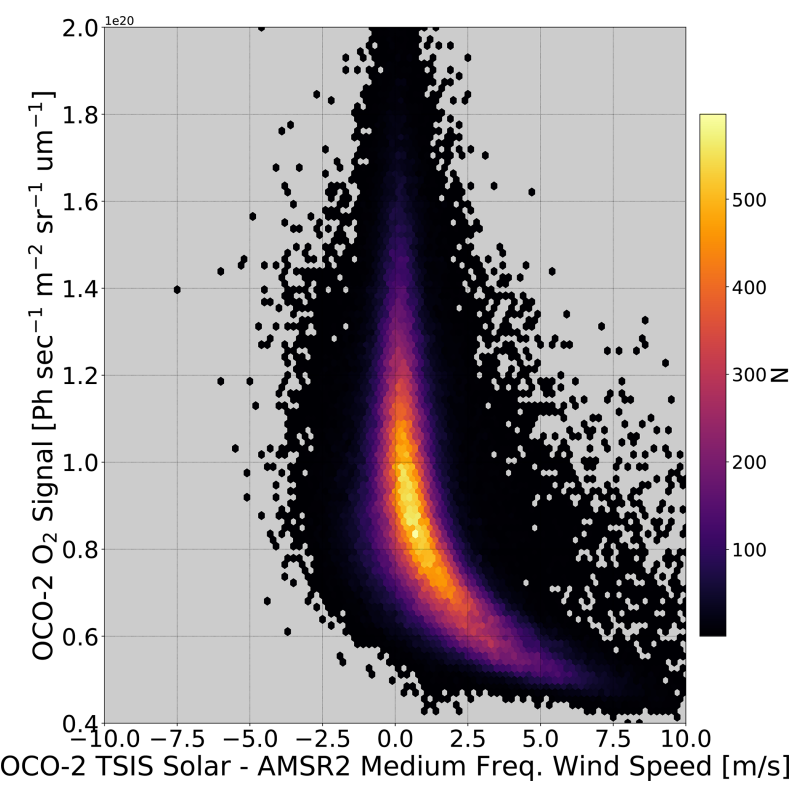

Figure 3. Heatmap of OCO-2 $\mathrm{O}_{2}$ A-band signal compared to wind speed difference (OCO-2 TSIS solar - AMSR2 medium frequency).

signed to cover the same temporal and spatial range as the full B9 dataset.

Despite the improvement in scatter and bias, the bias pattern in retrieved wind speed against AMSR2 persists. Figure 3 demonstrates that this high bias is strongly correlated with low signal levels. The $\mathrm{O}_{2} \mathrm{~A}$-band is plotted here, but the same relationship exists for the weak and strong $\mathrm{CO}_{2}$ bands.

\subsection{Three-band Cox-Munk only}

The next experiment was designed to test the hypothesis that solving for both the wind speed and a Lambertian component was inducing the mean high bias relative to AMSR2. This is because in the Cox-Munk plus Lambertian setup the retrieval has multiple ways to adjust the radiances to match the measured spectra. Specifically, it can adjust the wind speed but also adjust the Lambertian albedos and albedo slopes. Figure 3 suggests that the Cox-Munk plus Lambertian component results in the retrieval of erroneously large wind speed when the signals are low (i.e., when the wind speed is high). Here, we turn off the Lambertian component and force the retrieval to solve for one wind speed to fit the continuum for all three bands over water surfaces. Figure 4 shows that there is now a low bias of approximately $1 \mathrm{~m} \mathrm{~s}^{-1}$ but that $89.8 \%$ of the retrievals fail to converge.

Of note is that Fig. 5 demonstrates that removing the Lambertian component in the surface reflectance parameterization greatly reduces the dependency on signal seen in Fig. 3 . The noisier data in Fig. 5 relative to Fig. 3 are mostly due to a significant reduction in converged retrievals for this threeband Cox-Munk-only test.

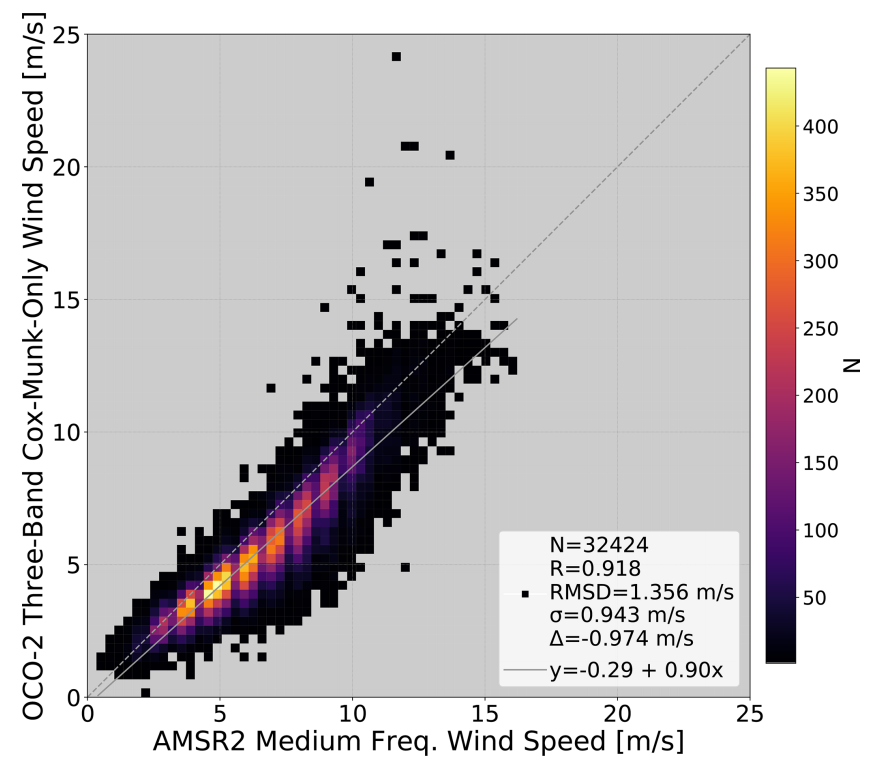

Figure 4. Heatmap of OCO-2 three-band Cox-Munk-only wind speed compared to AMSR2 medium-frequency wind speed. The B9 lite file quality flag and height scaling have been applied. The TSIS solar continuum is used. $N$ is the number of retrievals, $R$ is the correlation coefficient, RMSD is the root mean square deviation of the two datasets, $\sigma$ is the standard deviation between the two datasets, $\Delta$ is the mean difference, the dashed line is a one-to-one line, and $y$ is a linear fit plotted as a solid line.

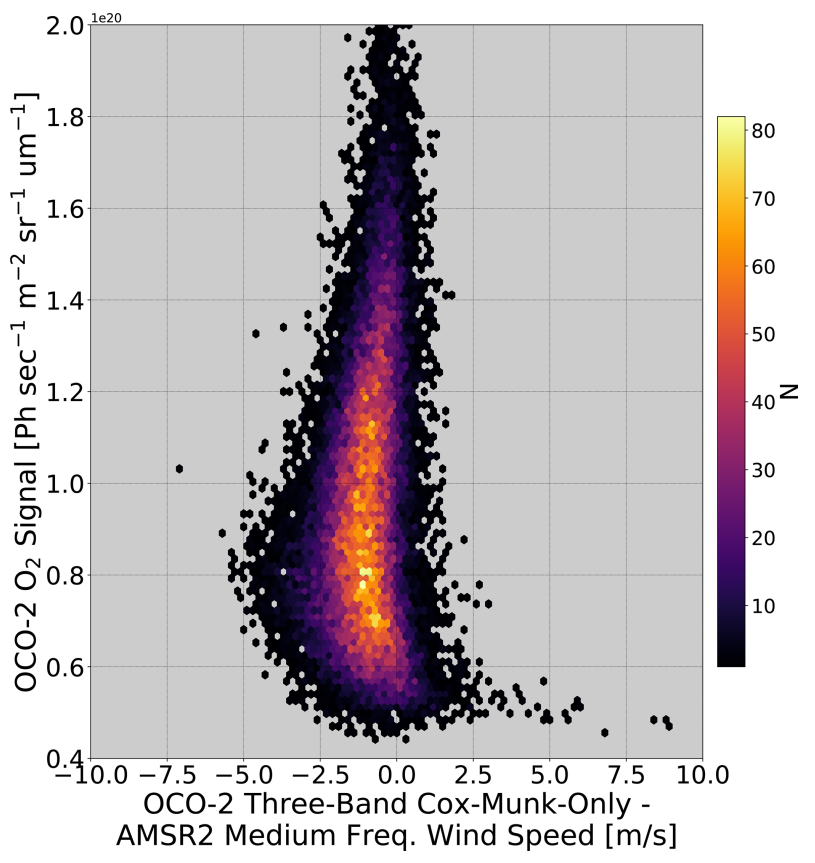

Figure 5. Heatmap of OCO-2 $\mathrm{O}_{2}$ A-band signal compared to wind speed difference (OCO-2 three-band Cox-Munk only - AMSR2 medium frequency). 


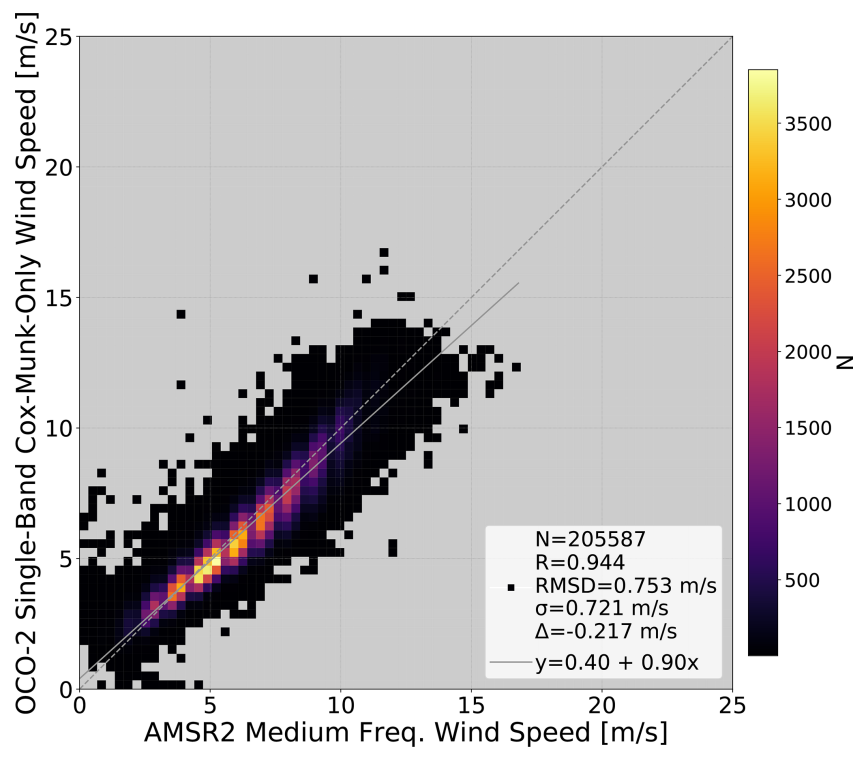

Figure 6. Heatmap of OCO-2 single-band Cox-Munk-only wind speed compared to AMSR2 medium-frequency wind speed. The B9 lite file quality flag, custom filtering, and height scaling have been applied. The TSIS solar continuum is used. $N$ is the number of retrievals, $R$ is the correlation coefficient, RMSD is the root mean square deviation of the two datasets, $\sigma$ is the standard deviation between the two datasets, $\Delta$ is the mean difference, the dashed line is a one-to-one line, and $y$ is a linear fit plotted as a solid line.

\subsection{Single-band Cox-Munk only}

The final test was designed to build upon the previous results and examine whether a single-band Cox-Munk-only retrieval could perform better compared to AMSR2, with the idea that one retrieved wind speed should be sufficient to fit the continuum of one OCO-2 band. In this test, only the $\mathrm{O}_{2}$ A-band was used. The $\mathrm{CO}_{2}$ retrieval was disabled, as neither of the $\mathrm{CO}_{2}$ bands were used. Empirical orthogonal functions, which are part of the usual ACOS state vector, were also disabled to create a retrieval that is as simple as possible. Figure 6 shows the results. The number of successful retrievals is much improved relative to the three-band version (Sect. 4.3), with $91.0 \%$ meeting the convergence criteria. In addition to using the B9 quality flag, additional filtering was employed to remove a small number of highly erroneous retrievals. The difference between the retrieved surface pressure and the prior surface pressure was filtered to exclude values outside of $\pm 8 \mathrm{hPa}$, retrieved ice cloud heights greater than 0.14 were removed, and air mass factors greater than 2.8 were removed. The bias against AMSR2 is reduced to $-0.22 \mathrm{~m} \mathrm{~s}^{-1}$ with an RMSD of $0.75 \mathrm{~m} \mathrm{~s}^{-1}$ and correlation coefficient of 0.94 .

This same single-band Cox-Munk-only test was repeated using the weak $\mathrm{CO}_{2}$ and strong $\mathrm{CO}_{2}$ channels independently, with mixed results. For the weak $\mathrm{CO}_{2}$ and strong $\mathrm{CO}_{2}$ versions the biases against AMSR2 were -0.90 and
$-0.74 \mathrm{~m} \mathrm{~s}^{-1}$ and the RMSDs were 1.27 and $1.27 \mathrm{~m} \mathrm{~s}^{-1}$, respectively. Finally, comparison statistics were regenerated but using the RSS low-frequency product (as discussed in Sect. 2). The statistics and shape of the distribution are similar, with a slightly worse bias ( -0.31 vs. $\left.-0.22 \mathrm{~m} \mathrm{~s}^{-1}\right)$ but somewhat improved scatter $\left(0.67\right.$ vs. $\left.0.72 \mathrm{~m} \mathrm{~s}^{-1}\right)$ and linear fit slope (0.90 vs. 0.94).

\section{Discussion and conclusions}

Here, we assessed how well near-infrared observations of reflected sunlight from OCO-2 could be used to estimate surface wind speeds in cloud-free regions. Table 1 gives a statistical summary of the retrievals tested.

It was found that the operational product (ACOS B9) is biased high against AMSR2, with the bias increasing at higher wind speeds. The inclusion of an updated solar continuum from the TSIS instrument onboard the ISS improved the comparison slightly but the high bias remained. The removal of the Lambertian component of the state vector resulted in the majority of retrievals failing to converge. This is probably because one wind speed is insufficient to fit the continuum radiances of all three OCO-2 bands, each with their own small calibration errors. A single-band Cox-Munk-only retrieval using the $\mathrm{O}_{2}$ A-band with the updated solar continuum and a small height adjustment gives wind speeds that compare very well to AMSR2, with an RMSD of $0.75 \mathrm{~m} \mathrm{~s}^{-1}$ and a correlation coefficient of 0.94 . These errors are less than the estimated errors of AMSR2 itself $\left(1-1.5 \mathrm{~m} \mathrm{~s}^{-1}\right)$, which may be partly because both sensors use similar assumptions about sea surface slope distributions and the relationship between these distributions, surface wind speed, and wind stress. Additionally, AMSR 2 errors have typically been estimated by comparing to buoys, which has its own set of challenges, including spatiotemporal matching errors, buoy height adjustment assumptions, and buoy measurement errors. Importantly, the retrieved wind speed shows better agreement to AMSR2 than the GEOS-5 FP-IT wind speed used as the OCO-2 meteorological prior, which has an RMSD of $1.18 \mathrm{~m} \mathrm{~s}^{-1}$ compared to AMSR2. The weak $\mathrm{CO}_{2}$ and strong $\mathrm{CO}_{2}$ versions of the single-band Cox-Munk-only test resulted in worse scatter and bias compared to the $\mathrm{O}_{2}$ A-band version. This result may be explained by small uncorrected calibration errors in those bands. Additionally, while the two RSS wind speed products (medium- and low-frequency) give slightly different statistics when comparing the instruments, the conclusion that a modified OCO- 2 retrieval can accurately and precisely measure wind speed holds true.

Another possible contribution to the differences between OCO-2 and AMSR2 is that the OCO-2 glint off-pointing strategy is not optimized to be maximally sensitive to the wind speed. This is because OCO-2 points further away from the glint spot at higher viewing angles while simultaneously the actual glint spot gets larger in size with faster 
Table 1. Summary of the retrieval tests performed. Percent converged represents the fraction of converged soundings for the three retrieval variants, which were run on a set of soundings that were chosen to contain only high-quality soundings. The TSIS solar test was run on a slightly different set of soundings than the three- and single-band Cox-Munk-only tests. The ACOS B9 retrieval was run on a very large set of less filtered soundings, and thus the percent of converged soundings is not comparable to the other three tests. The ACOS B9 retrieval was run on a very large set of less filtered soundings and the percent of converged soundings is not comparable to the other three tests, so it is listed as "not applicable" (n/a).

\begin{tabular}{lrrrr}
\hline Retrieval & $\begin{array}{r}\text { Percent } \\
\text { converged }\end{array}$ & $\begin{array}{r}\text { Bias } \\
\left(\mathrm{m} \mathrm{s}^{-1}\right)\end{array}$ & $\begin{array}{r}\sigma \\
\left(\mathrm{m} \mathrm{s}^{-1}\right)\end{array}$ & $\begin{array}{r}\text { RMSD } \\
\left(\mathrm{m} \mathrm{s}^{-1}\right)\end{array}$ \\
\hline ACOS B9 & $\mathrm{n} / \mathrm{a}$ & 1.807 & 1.818 & 2.563 \\
TSIS solar & 93.6 & 1.149 & 1.685 & 2.039 \\
Three-band Cox-Munk only & 10.2 & -0.974 & 0.943 & 1.356 \\
Single-band Cox-Munk only & 91.0 & -0.217 & 0.721 & 0.753 \\
\hline
\end{tabular}

wind speeds. This results in situations where windier scenes can be brighter than calm scenes at certain OCO-2 viewing angles. Ideally, OCO-2 would point directly at the glint spot to avoid this issue, but this risks damaging the instrument.

As discussed in Sect. 2, the footprint size of OCO$2(1.25 \mathrm{~km}$ by $2 \mathrm{~km}$ at nadir) is much smaller than that of AMSR2 $\left(0.25^{\circ}\right.$ latitude-longitude grid). Inherently, this means there will be more variability in the OCO-2 wind speeds. In order to quantify the impact, we calculated the overpass mean wind speed for each AMSR2 measurement, i.e., the average wind speed of all OCO-2 footprints within a given AMSR2 grid cell. The difference statistics of this smoothed value compared to AMSR2 were similar to those of the unaveraged values, suggesting that the difference in spatial resolution of the two sensors does not significantly impact the overall results of this study.

To extend the analysis beyond global statistics, Fig. 7 shows the difference between OCO-2 and AMSR2 wind speeds as a function of time and latitude. It shows a latitude dependance of the differences. There are multiple hypotheses that could explain this pattern. The Cox-Munk parameterization was developed on measurements restricted to solar zenith angles less than $35^{\circ}$, while OCO- 2 views the glint spot at solar zenith angles from around $16^{\circ}$ to upwards of $70^{\circ}$ and looks further away from the glint spot as the angle increases. As the solar zenith angle is closely tied to latitude, this could explain the low bias at high latitudes, and indeed some of the low-biased retrievals are removed with the air mass filter described in Sect. 4.4. Besides viewing geometry, numerous studies have suggested that the relationship between reflectivity and wind speed derived by Cox and Munk (1954) depends on atmospheric stability (Haimbach and $\mathrm{Wu}, 1985$; Hwang and Shemdin, 1988; Shaw and Churnside, 1997). They found that stable air suppressed ripples and subsequently would produce a lower wind speed estimate and vice versa. However, additional study is needed to determine if, for example, the OCO-2 high bias seen in parts of the tropics in Fig. 7 is associated with unstable air. Finally, the isotropic simplification by Cox and Munk used in our retrieval means that wind direction is not taken into

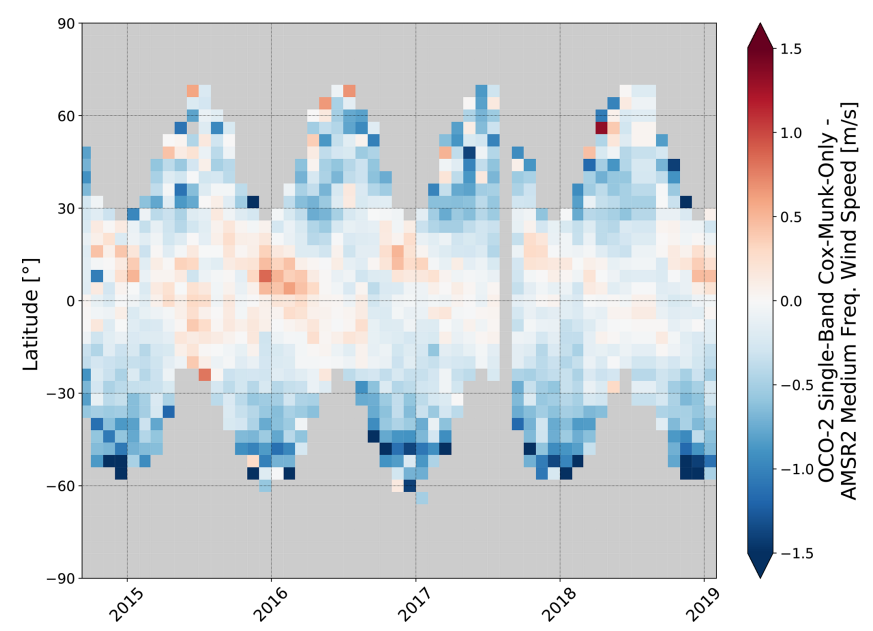

Figure 7. Heatmap of OCO-2 single-band Cox-Munk-only wind speed compared to AMSR2 medium-frequency wind speed as a function of time and latitude. The B9 lite file quality flag, custom filtering, and height scaling have been applied. The TSIS solar continuum is used.

account; thus, the estimated wind speed could vary slightly depending on if the sensor is viewing upwind, downwind, or crosswind. However, we analyzed the spatial patterns of the difference between the sensor azimuth angle and the meteorological wind direction (not used in the retrieval) and found no obvious correlation with the wind speed differences.

There have been many other critiques and attempts to improve the Cox-Munk parameterization (e.g., Wu, 1972, 1990; Wentz, 1976; Ebuchi and Kizu, 2002; Tatarskii, 2003; Bréon and Henriot, 2006; see Zhang and Wang, 2010, for an overview), but in general it is still widely used in remote sensing to describe the reflection of sunlight off of water. Improvements to the original parameterization, including new ways of fitting the data and the inclusion of additional measurements, could explain some of the remaining differences between OCO-2 and AMSR2, but it is beyond the scope of this work to implement them. 
There are a number of potential applications for accurate and precise wind speeds from OCO-2. The small footprint size of approximately $1.25 \mathrm{~km}$ by $2 \mathrm{~km}$ at nadir allows for the detection of wind speed closer to coasts than microwave radiometers, which currently have resolutions on the order of $25 \mathrm{~km}$ and are thus unable to view close to coastlines. Bourassa et al. (2019) note that "hydraulic expansion fans in the marine boundary layer near capes and points (Winant et al., 1988; Rahn and Garreaud, 2014; Parish et al., 2016), coastally trapped wind reversals (Nuss et al., 2000), and alongshore wind jets confined by coastal mountains can have cross-coast scales of 5-10 km or smaller" and that we have limited knowledge of all of these features. Highresolution wind speed measurements would be able to detect winds much closer to coastlines and advance our understanding of these processes. Several economic sectors could also benefit from near-coast wind speed measurements, including oil-spill response, wind energy forecasting, and search and rescue operations. Bourassa et al. (2019) write that the current plan to enhance spatial coverage from microwave sensors is to reduce onboard data averaging, but a wideswath OCO-2-like instrument could provide highly accurate wind speed measurements near the coast in clear-sky conditions, depending on the viewing capabilities. Further study is needed to confirm the quality of these OCO-2 near-coast measurements, e.g., by comparing to buoy wind speeds, as shallow waters and turbidity may impact the retrieval in the $\mathrm{O}_{2}$ A-band. (The $\mathrm{CO}_{2}$ bands will be less impacted, as they have penetration depths of less than $1 \mathrm{~mm}$.) It should be noted that certain active wind speed sensors, specifically altimeters, have footprints on the order of 1-10 km (Zieger et al., 2009). However, their coverage is limited; thus, OCO-2 would provide useful complementary measurements.

Additionally, wind speed measurements at different times of day could help constrain the diurnal cycle of ocean winds. OCO-3, which is the backup of OCO-2 and currently deployed on the ISS, also makes glint measurements, but these wind speed measurements span the entire daytime due to the ISS's precessing orbit. Additional work is needed to validate the retrieved wind speed from OCO- 3 , but the instrument has characteristics very similar to OCO-2; thus, it is likely that the conclusions found here are also valid for OCO-3. Finally, this work will inform a number of future OCO-2-like instruments, such as MicroCarb (Buil et al., 2011) and the ambitious Copernicus $\mathrm{CO}_{2}$ Monitoring Mission (Sierk et al., 2019).

Code and data availability. The OCO-2 L2 Full Physics Code is open-source code and is available on GitHub https://github.com/ nasa/RtRetrievalFramework (last access: 7 May 2020; NASA, 2020), and corresponding user's guide is available at http://nasa. github.io/RtRetrievalFrameworkDoc/ (last access: 7 May 2020; California Institute of Technology, 2020). All of the OCO-2 data products are publicly available through the NASA Goddard Earth
Science Data and Information Services Center (GES DISC) for distribution and archiving (https://doi.org/10.5067/6SBROTA57TFH, OCO-2 Science Team et al., 2020).

Author contributions. RRN designed and performed the experiments. AE helped supervise the project. DC, AJM, and CWO'D contributed to the interpretation of the results. RRN wrote the article with contributions from all authors.

Competing interests. The authors declare that they have no conflict of interest.

Acknowledgements. The authors would like to thank the editor and the two reviewers for providing useful comments and feedback on this paper.

Financial support. This research has been supported by the Jet Propulsion Laboratory, California Institute of Technology (grant no. 80NM0018D0004).

Review statement. This paper was edited by Ad Stoffelen and reviewed by François-Marie Bréon and one anonymous referee.

\section{References}

Born, G. H., Dunne, J. A., and Lame, D. B.: Seasat mission overview, Science, 204, 1405-1406, https://doi.org/10.1126/science.204.4400.1405, 1979.

Bourassa, M. A., Gille, S. T., Jackson, D. L., Roberts, J. B., and Wick, G. A.: Ocean winds and turbulent air-sea fluxes inferred from remote sensing, Oceanography, 23, 36-51, https://doi.org/10.5670/oceanog.2010.04, 2010.

Bourassa, M. A., Meissner, T., Cerovecki, I., Chang, P. S., Dong, X., Chiara, G. D., Donlon, C., Dukhovskoy, D. S., Elya, J., Fore, A., Fewings, M. R., Foster, R. C., Gille, S. T., Haus, B. K., HristovaVeleva, S., Holbach, H. M., Jelenak, Z., Knaff, J. A., Kranz, S. A., Manaster, A., Mazloff, M., Mears, C., Mouche, A., Portabella, M., Reul, N., Ricciardulli, L., Rodriguez, E., Sampson, C., Solis, D., Stoffelen, A., Stukel, M. R., Stiles, B., Weissman, D. and Wentz, F.: Remotely sensed winds and wind stresses for marine forecasting and ocean modeling, Front. Mar. Sci., 6, 443, https://doi.org/10.3389/fmars.2019.00443, 2019.

Bréon, F. and Henriot, N.: Spaceborne observations of ocean glint reflectance and modeling of wave slope distributions, J. Geophys. Res.-Oceans, 111, C06005, https://doi.org/10.1029/2005JC003343, 2006.

Buil, C., Pascal, V., Loesel, J., Pierangelo, C., Roucayrol, L., and Tauziede, L.: A new space instrumental concept for the measurement of $\mathrm{CO}_{2}$ concentration in the atmosphere, in: Sensors, Systems, and Next-Generation Satellites XV, vol. 8176, 817621, International Society for Optics and Photonics, https://doi.org/10.1117/12.897598, 2011. 
California Institute of Technology: RT Retrieval Framework, available at: http://nasa.github.io/RtRetrievalFrameworkDoc/, last access: 7 May 2020.

Cox, C. and Munk, W.: Measurement of the Roughness of the Sea Surface from Photographs of the Sun's Glitter, J. Opt. Soc. Am., 44, 838-850, https://doi.org/10.1364/JOSA.44.000838, 1954.

Crisp, D., Miller, C. E., and DeCola, P. L.: NASA Orbiting Carbon Observatory: measuring the column averaged carbon dioxide mole fraction from space, J. Appl. Remote Sens., 2, 023508, https://doi.org/10.1117/1.2898457, 2008.

Crisp, D., Fisher, B. M., O’Dell, C., Frankenberg, C., Basilio, R., Bösch, H., Brown, L. R., Castano, R., Connor, B., Deutscher, N. M., Eldering, A., Griffith, D., Gunson, M., Kuze, A., Mandrake, L., McDuffie, J., Messerschmidt, J., Miller, C. E., Morino, I., Natraj, V., Notholt, J., O’Brien, D. M., Oyafuso, F., Polonsky, I., Robinson, J., Salawitch, R., Sherlock, V., Smyth, M., Suto, H., Taylor, T. E., Thompson, D. R., Wennberg, P. O., Wunch, D., and Yung, Y. L.: The ACOS $\mathrm{CO}_{2}$ retrieval algorithm - Part II: Global $X_{\mathrm{CO}_{2}}$ data characterization, Atmos. Meas. Tech., 5, 687707, https://doi.org/10.5194/amt-5-687-2012, 2012.

Crisp, D., Pollock, H. R., Rosenberg, R., Chapsky, L., Lee, R. A. M., Oyafuso, F. A., Frankenberg, C., O’Dell, C. W., Bruegge, C. J., Doran, G. B., Eldering, A., Fisher, B. M., Fu, D., Gunson, M. R., Mandrake, L., Osterman, G. B., Schwandner, F. M., Sun, K., Taylor, T. E., Wennberg, P. O., and Wunch, D.: The on-orbit performance of the Orbiting Carbon Observatory-2 (OCO-2) instrument and its radiometrically calibrated products, Atmos. Meas. Tech., 10, 59-81, https://doi.org/10.5194/amt-10-59-2017, 2017.

Draper, D. W., Newell, D. A., Wentz, F. J., Krimchansky, S., and Skofronick-Jackson, G. M.: The global precipitation measurement (GPM) microwave imager (GMI): Instrument overview and early on-orbit performance, IEEE J. Sel. Top. Appl., 8, 34523462, https://doi.org/10.1109/JSTARS.2015.2403303, 2015.

Durden, S. L. and Perkovic-Martin, D.: The RapidScat ocean winds scatterometer: A radar system engineering perspective, IEEE Geosci. Remote S. Mag., 5, 36-43, https://doi.org/10.1109/MGRS.2017.2678999, 2017.

Ebuchi, N.: Evaluation of wind speed globally observed by AMSR 2 on GCOM-W1, in: 2014 IEEE International Geoscience and Remote Sensing Symposium-IGARSS, 1318 July 2014, Quebec City, QC, Canada, 3902-3905, https://doi.org/10.1109/IGARSS.2014.6947337, 2014.

Ebuchi, N. and Kizu, S.: Probability distribution of surface wave slope derived using sun glitter images from geostationary meteorological satellite and surface vector winds from scatterometers, J. Oceanogr., 58, 477-486, https://doi.org/10.1023/A:1021213331788, 2002.

Figa-Saldaña, J., Wilson, J. J., Attema, E., Gelsthorpe, R., Drinkwater, M. R., and Stoffelen, A.: The advanced scatterometer (ASCAT) on the meteorological operational (MetOp) platform: A follow on for European wind scatterometers, Can. J. Remote Sens., 28, 404-412, https://doi.org/10.5589/m02-035, 2002.

Friedman, D.: Infrared characteristics of ocean water $(1.5-15 \mu)$ Appl. Optics, 8, 2073-2078, https://doi.org/10.1364/AO.8.002073, 1969.

Haimbach, S. and Wu, J.: Field trials of an optical scanner for studying sea-surface fine structures, IEEE J. Oceanic Engin., 10, 451453, https://doi.org/10.1109/JOE.1985.1145129, 1985.
Hale, G. M. and Querry, M. R.: Optical constants of water in the 200-nm to 200- $\mu \mathrm{m}$ wavelength region, Appl. Optics, 12, 555563, https://doi.org/10.1364/AO.12.000555, 1973.

Hollinger, J. P., Peirce, J. L., and Poe, G. A.: SSM/I instrument evaluation, IEEE T. Geosci. Remote, 28, 781-790, https://doi.org/10.1109/36.58964, 1990.

Hwang, P. A. and Shemdin, O. H.: The dependence of sea surface slope on atmospheric stability and swell conditions, J. Geophys. Res.-Oceans, 93, 13903-13912, https://doi.org/10.1029/JC093iC11p13903, 1988.

Imaoka, K., Kachi, M., Kasahara, M., Ito, N., Nakagawa, K., and Oki, T.: Instrument performance and calibration of AMSR-E and AMSR2, International Archives of the Photogrammetry, Remote Sensing and Spatial Information Science, 38, 13-18, 2010.

Kachi, M., Naoki, K., Hori, M., and Imaoka, K.: AMSR2 validation results, in: 2013 IEEE International Geoscience and Remote Sensing Symposium - IGARSS, 2126 July 2013, Melbourne, VIC, Australia, IEEE, 831-834, https://doi.org/10.1109/IGARSS.2013.6721287, 2013.

Kay, S., Hedley, J. D., and Lavender, S.: Sun glint correction of high and low spatial resolution images of aquatic scenes: a review of methods for visible and near-infrared wavelengths, Remote Sens., 1, 697-730, https://doi.org/10.3390/rs1040697, 2009.

L'Ecuyer, T. S. and Jiang, J. H.: Touring the atmosphere aboard the A-Train, Phys. Today, 63, 36-41, https://doi.org/10.1063/1.3463626, 2010.

Lillibridge, J., Scharroo, R., Abdalla, S., and Vandemark, D.: One-and two-dimensional wind speed models for Kaband altimetry, J. Atmos. Ocean. Tech., 31, 630-638, https://doi.org/10.1175/JTECH-D-13-00167.1, 2014.

McLellan, H. J.: Elements of physical oceanography, Pergamon Press, Elmsford, New York, USA, 1965.

Mears, C., Smith, D. K., and Wentz, F. J.: Comparison of special sensor microwave imager and buoy-measured wind speeds from 1987 to 1997, J. Geophys. Res.-Oceans, 106, 11719-11729, https://doi.org/10.1029/1999JC000097, 2001.

Meftah, M., Damé, L., Bolsée, D., Pereira, N., Sluse, D., Cessateur, G., Irbah, A., Sarkissian, A., Djafer, D., Hauchecorne, A., and Bekki, S.: A New Solar Spectrum from 656 to $3088 \mathrm{~nm}$, Sol. Phys., 292, 101, https://doi.org/10.1007/s11207-017-11152, 2017.

Meissner, T. and Wentz, F. J.: The emissivity of the ocean surface between 6 and $90 \mathrm{GHz}$ over a large range of wind speeds and earth incidence angles, IEEE T. Geosci. Remote, 50, 3004-3026, https://doi.org/10.1109/TGRS.2011.2179662, 2012.

Monzon, C., Forester, D. W., Burkhart, R., and Bellemare, J.: Rough ocean surface and sunglint region characteristics, Appl. Optics, 45, 7089-7096, https://doi.org/10.1364/AO.45.007089, 2006.

NASA: RtRetrievalFramework, GitHub, available at: https://github. com/nasa/RtRetrievalFramework, last access: 7 May 2020.

Nuss, W. A., Bane, J. M., Thompson, W. T., Holt, T., Dorman, C. E., Ralph, F. M., Rotunno, R., Klemp, J. B., Skamarock, W. C., Samelson, R. M., Rogerson, A. M., Reason, C., and Jackson, P.: Coastally trapped wind reversals: Progress toward understanding, B. Am. Meteorol. Soc., 81, 719-744, https://doi.org/10.1175/15200477(2000)081<0719:CTWRPT>2.3.CO;2, 2000.

OCO-2 Science Team/Gunson, M., and Eldering, A.: OCO-2 Level 2 geolocated XCO2 retrievals results, physical model, Retro- 
spective Processing V10r, Greenbelt, MD, USA, Goddard Earth Sciences Data and Information Services Center (GES DISC), https://doi.org/10.5067/6SBROTA57TFH, 2020.

O’Dell, C. W., Connor, B., Bösch, H., O’Brien, D., Frankenberg, C., Castano, R., Christi, M., Eldering, D., Fisher, B., Gunson, M., McDuffie, J., Miller, C. E., Natraj, V., Oyafuso, F., Polonsky, I., Smyth, M., Taylor, T., Toon, G. C., Wennberg, P. O., and Wunch, D.: The ACOS $\mathrm{CO}_{2}$ retrieval algorithm - Part 1: Description and validation against synthetic observations, Atmos. Meas. Tech., 5, 99-121, https://doi.org/10.5194/amt-5-99-2012, 2012.

O’Dell, C. W., Eldering, A., Wennberg, P. O., Crisp, D., Gunson, M. R., Fisher, B., Frankenberg, C., Kiel, M., Lindqvist, H., Mandrake, L., Merrelli, A., Natraj, V., Nelson, R. R., Osterman, G. B., Payne, V. H., Taylor, T. E., Wunch, D., Drouin, B. J., Oyafuso, F., Chang, A., McDuffie, J., Smyth, M., Baker, D. F., Basu, S., Chevallier, F., Crowell, S. M. R., Feng, L., Palmer, P. I., Dubey, M., García, O. E., Griffith, D. W. T., Hase, F., Iraci, L. T., Kivi, R., Morino, I., Notholt, J., Ohyama, H., Petri, C., Roehl, C. M., Sha, M. K., Strong, K., Sussmann, R., Te, Y., Uchino, O., and Velazco, V. A.: Improved retrievals of carbon dioxide from Orbiting Carbon Observatory-2 with the version 8 ACOS algorithm, Atmos. Meas. Tech., 11, 6539-6576, https://doi.org/10.5194/amt11-6539-2018, 2018.

Parashar, S., Langham, E., McNally, J., and Ahmed, S.: RADARSAT mission requirements and concept, Can. J. Remote Sens., 19, 280-288, https://doi.org/10.1080/07038992.1993.10874563, 1993.

Parish, T. R., Rahn, D. A., and Leon, D. C.: Aircraft measurements and numerical simulations of an expansion fan off the California coast, J. Appl. Meteorol. Clim., 55, 2053-2062, https://doi.org/10.1175/JAMC-D-16-0101.1, 2016.

Rahn, D. A. and Garreaud, R. D.: A synoptic climatology of the near-surface wind along the west coast of South America, Int. J. Climatol., 34, 780-792, https://doi.org/10.1002/joc.3724, 2014.

Ricciardulli, L. and Wentz, F. J.: A scatterometer geophysical model function for climate-quality winds: QuikSCAT Ku-2011, J. Atmos. Ocean. Tech., 32, 1829-1846, https://doi.org/10.1175/JTECH-D-15-0008.1, 2015.

Rienecker, M. M., Suarez, M. J., Todling, R., Bacmeister, J., Takacs, L., Liu, H.-C., Gu, W., Sienkiewicz, M., Koster, R. D., Gelaro, R., Stajner, I., and Nielsen, J. E.: The GEOS-5 Data Assimilation System-Documentation of Versions 5.0.1, 5.1.0, and 5.2.0, Tech. rep., NASA Goddard Space Flight Center, Greenbelt, MD, available at: https://ntrs.nasa.gov/archive/nasa/ casi.ntrs.nasa.gov/20120011955.pdf (last access: 7 May 2020), 2008.

Rodgers, C. D.: Inverse Methods for Atmospheric Sounding: Theory and Practice, World Scientific, Singapore, 2000.

Rosenqvist, A., Shimada, M., Ito, N., and Watanabe, M.: ALOS PALSAR: A pathfinder mission for global-scale monitoring of the environment, IEEE T. Geosci. Remote, 45, 3307-3316, https://doi.org/10.1109/TGRS.2007.901027, 2007.

Shaw, J. A. and Churnside, J. H.: Scanning-laser glint measurements of sea-surface slope statistics, Appl. Optics, 36, 42024213, https://doi.org/10.1364/AO.36.004202, 1997.

Sierk, B., Bézy, J.-L., Löscher, A., and Meijer, Y.: The European $\mathrm{CO}_{2}$ Monitoring Mission: observing anthropogenic greenhouse gas emissions from space, in: International Conference on Space Optics - ICSO 2018, 12 July 2019, Chania, Greece, vol.
11180, 111800M, International Society for Optics and Photonics, https://doi.org/10.1117/12.2535941, 2019.

Spencer, M. W., Wu, C., and Long, D. G.: Improved resolution backscatter measurements with the SeaWinds pencilbeam scatterometer, IEEE T. Geosci. Remote, 38, 89-104, https://doi.org/10.1109/36.823904, 2000.

Stull, R. B.: An introduction to boundary layer meteorology, vol. 1, Springer Science and Business Media, Dordrecht, the Netherlands, 1988.

Su, W., Charlock, T. P., and Rutledge, K.: Observations of reflectance distribution around sunglint from a coastal ocean platform, Appl. Optics, 41, 7369-7383, https://doi.org/10.1364/AO.41.007369, 2002.

Sverdrup, H., Johnson, M., and Fleming, R.: Chemistry of sea water, The oceans: their physics, chemistry, and general biology, Prentice-Hall, New York City, USA, 165-227, 1942.

Tatarskii, V. I.: Multi-Gaussian representation of the CoxMunk distribution for slopes of wind-driven waves, J. Atmos. Ocean. Tech., 20, 1697-1705, https://doi.org/10.1175/15200426(2003)020<1697:MROTCD>2.0.CO;2, 2003.

Taylor, T. E., O'Dell, C. W., Frankenberg, C., Partain, P. T., Cronk, H. Q., Savtchenko, A., Nelson, R. R., Rosenthal, E. J., Chang, A. Y., Fisher, B., Osterman, G. B., Pollock, R. H., Crisp, D., Eldering, A., and Gunson, M. R.: Orbiting Carbon Observatory-2 (OCO-2) cloud screening algorithms: validation against collocated MODIS and CALIOP data, Atmos. Meas. Tech., 9, 973989, https://doi.org/10.5194/amt-9-973-2016, 2016.

Thuillier, G., Hersé, M., Labs, D., Foujols, T., Peetermans, W., Gillotay, D., Simon, P., and Mandel, H.: The solar spectral irradiance from 200 to $2400 \mathrm{~nm}$ as measured by the SOLSPEC spectrometer from the ATLAS and EURECA missions, Sol. Phys., 214, 1-22, https://doi.org/10.1023/A:1024048429145, 2003.

Wentz, F. J.: Cox and Munk's sea surface slope variance, J. Geophys. Res., 81, 1607-1608, https://doi.org/10.1029/JC081i009p01607, 1976.

Wentz, F. J.: A well-calibrated ocean algorithm for special sensor microwave/imager, J. Geophys. Res.-Oceans, 102, 8703-8718, https://doi.org/10.1029/96JC01751, 1997.

Wentz, F. J.: A 17-yr climate record of environmental parameters derived from the Tropical Rainfall Measuring Mission (TRMM) Microwave Imager, J. Climate, 28, 6882-6902, https://doi.org/10.1175/JCLI-D-15-0155.1, 2015.

Wentz, F. J. and Draper, D.: On-orbit absolute calibration of the global precipitation measurement microwave imager, J. Atmos. Ocean. Tech., 33, 1393-1412, https://doi.org/10.1175/JTECHD-15-0212.1, 2016.

Wentz, F. J., Ricciardulli, L., Rodriguez, E., Stiles, B. W., Bourassa, M. A., Long, D. G., Hoffman, R. N., Stoffelen, A., Verhoef, A., O’Neill, L. W., Farrar, J. T., Vandemark, D., Fore, A. G., Hristova-Veleva, S. M., Turk, F. J., Gaston, R., and Tyler, D.: Evaluating and extending the ocean wind climate data record, IEEE J. Sel. Top Appl., 10, 2165-2185, https://doi.org/10.1109/JSTARS.2016.2643641, 2017.

Winant, C., Dorman, C., Friehe, C., and Beardsley, R.: The marine layer off northern California: An example of supercritical channel flow, J. Atmos. Sci., 45, 3588-3605, https://doi.org/10.1175/15200469(1988)045<3588:TMLONC>2.0.CO;2, 1988. 
Wu, J.: Sea-surface slope and equilibrium wind-wave spectra, Phys. Fluids, 15, 741-747, https://doi.org/10.1063/1.1693978, 1972.

$\mathrm{Wu}, \mathrm{J} .:$ Mean square slopes of the wind-disturbed water surface, their magnitude, directionality, and composition, Radio Sci., 25, 37-48, https://doi.org/10.1029/RS025i001p00037, 1990.
Zhang, H. and Wang, M.: Evaluation of sun glint models using MODIS measurements, J. Quant. Spectrosc. Ra., 111, 492-506, https://doi.org/10.1016/j.jqsrt.2009.10.001, 2010.

Zieger, S., Vinoth, J., and Young, I.: Joint calibration of multiplatform altimeter measurements of wind speed and wave height over the past 20 years, J. Atmos. Ocean. Tech., 26, 2549-2564, https://doi.org/10.1175/2009JTECHA1303.1, 2009. 